University of Nebraska - Lincoln

DigitalCommons@University of Nebraska - Lincoln

Publications from USDA-ARS / UNL Faculty

U.S. Department of Agriculture: Agricultural

Research Service, Lincoln, Nebraska

2017

Extreme Weather, Biotechnology, and Corn Productivity

Jonathan R. McFadden

USDA - Economic Research Service, jonathan.mcfadden@ers.usda.gov

John A. Miranowski

lowa State University, jmirski@iastate.edu

Follow this and additional works at: https://digitalcommons.unl.edu/usdaarsfacpub

McFadden, Jonathan R. and Miranowski, John A., "Extreme Weather, Biotechnology, and Corn

Productivity" (2017). Publications from USDA-ARS / UNL Faculty. 1799.

https://digitalcommons.unl.edu/usdaarsfacpub/1799

This Article is brought to you for free and open access by the U.S. Department of Agriculture: Agricultural Research Service, Lincoln, Nebraska at DigitalCommons@University of Nebraska - Lincoln. It has been accepted for inclusion in Publications from USDA-ARS / UNL Faculty by an authorized administrator of DigitalCommons@University of Nebraska - Lincoln. 


\title{
Extreme Weather, Biotechnology, and Corn Productivity
}

\author{
Jonathan R. McFadden and John A. Miranowski
}

\begin{abstract}
U.S. agriculture has made impressive strides over the past 50 years in crop yield and input productivity growth, especially since the advent of geneticallymodified crops in 1996. However, future growth rates could decline if U.S. agriculture does not sufficiently adapt to climate change. We examine the magnitudes of weather impacts on U.S. corn yields during 1960-2011—with a focus on intense precipitation and nitrogen use efficiency-and use the empirical results to forecast yields for the subsequent 20 years (2012-2031). We improve upon past methodologies by employing dynamic Bayesian regressions. These dynamic models permit rapid updating of new information, consistent with both pronounced yield growth in recent years and agricultural adaptation to changing growing conditions. We find that corn yields will increase by $27-41 \%$ over 2011 yields in top-growing states, though yields will gradually decline in less-productive states where climate change impacts could be among the most harmful. Our forecasts are generally robust to the empirical specification and assumptions about the econometric disturbance term, and have similar out-of-sample performance. To the extent that increasingly intense rainfall could contribute to nitrogen and other nutrient leaching, farmers may need to adjust nutrient applications in response to changing production environments.
\end{abstract}

Keywords Corn yields $\cdot$ Climate change $\cdot$ Biotechnology $\cdot$ Intense precipitation Nitrogen use efficiency $\cdot$ Bayesian dynamic models $\cdot$ Information updating

\footnotetext{
J.R. McFadden

Economic Research Service, U.S. Dept. of Agriculture, 1400 Independence Avenue SW, Mail Stop 1800, Washington, DC 20250-0002, USA

e-mail: jonathan.mcfadden@ers.usda.gov

J.A. Miranowski ( $\varangle)$

Department of Economics, Iowa State University, 382B Heady Hall, Ames,

IA 50011-1054, USA

e-mail: jmirski@iastate.edu 


\section{Introduction}

U.S. agriculture has made impressive strides over the last 50 years in crop yield and productivity growth, and this growth has been even more impressive since the advent of biotechnology introduced in 1996. No crop has been more important than corn in the U.S. biotechnology era, although other crops have also realized significant productivity gains. The productivity impacts of biotechnology have been even more important in developing countries where farmers have less control of the production environment. An excellent review of the potential and contribution of geneticallymodified crops can be found in Barrows et al. [2].

The economics of corn farming in the United States has been evolving since the latter half of the twentieth century. In 1960, the U.S. harvested roughly 4 billion bushels of corn from 71 million acres, with approximately 1.6 million tons of nitrogen and 29 million pounds of pesticides (active ingredients) applied to corn. In more recent years, the U.S. has harvested 12-13 billion bushels from 87 million acres, while nitrogen and pesticides applied to corn have increased to 5.6 million tons and 204 million pounds, respectively (NASS [37]; Fernandez-Cornejo et al. [13]). Average U.S. corn yields have tripled over this period, up from $55 \mathrm{bu} / \mathrm{ac}$ in 1960 to 140-170 bu/ac in modern times (NASS [37]). The current dynamic context of US corn farming is one of increasing yields and increasing nitrogen use efficiency amidst stableor slowly-increasing acreage allocations. These substantial changes are largely the result of initial development and later widespread adoption of biotechnologies and new information technologies.

Since the commercial introduction of Bt corn (using the soil bacterium, Bacillus thuringiensis) in 1996, research and development (R\&D) of genetically-engineered seeds has brought significant development of new traits and multiple trait stacking. As of 2013, 76 percent of U.S. corn farmers planted Bt corn, and 85 percent planted herbicide-tolerant (HT) varieties, permitting more effective and less-costly weed control (Fernandez-Cornejo et al. [14]). Rapid farm-level adoption reflects that biotechnologies: (i) improve marginal productivities of several agricultural inputs, (ii) alter the optimal combinations of inputs and natural resources, and (iii) increase farm profitability. More efficient uptake and use of water and nitrogen by geneticallyengineered corn plants have boosted nitrogen use efficiency and land productivity. Biotechnology, coupled with changes in other management practices such as decreases in row spacing and higher seeding rates, have contributed directly to higher yields. In turn, this has largely obviated the need to expand cropland acreage and significantly expand nitrogen applications to keep pace with rising food demand. As output expands and optimal input use remains relatively unchanged or declines, variable profits have slowly risen (Fernandez-Cornejo and Wechsler [12]). Although the general equilibrium effects are difficult to disentangle, aggregate adoption of biotechnology and related inputs will likely increase input productivity and market incentives that drive further R\&D investment in the industry.

The advent of new information and data-based technologies are also complementing yield growth in the last decade. As with biotechnology, they influence marginal 
productivities of other production inputs, thereby changing the optimal input mix and ultimately farm output. For example, yield monitors are used to inform annual management decisions by improving nutrient use, pest control, energy, and operating efficiency. In the longer run, investments in irrigation, drainage, and capital equipment, ensure more accurate and efficient in-field operations. Variable rate applicators and guidance systems ensure optimal quantity and placement of seeds, fertilizer, and chemicals and reduce labor, energy, and machinery costs. Advances in information technologies complement biotechnologies and enhance marginal productivities of all inputs. As R\&D expands and input costs decline, agriculture will benefit from continued use of bio- and information technologies, especially under changing climate conditions.

While bio-and information-technology developments are improving, yield and productivity growth may be partially or totally offset by climate change (Schlenker and Roberts [46]; Lobell et al. [25]). Accompanying corn yield and productivity growth has been fundamental and often adverse changes in weather inputs [32]. Much of the U.S. experienced an average temperature increase of roughly $1^{\circ} \mathrm{C}$ or higher during 1901-2012. Annual precipitation during 1950-2010 increased by 5-25 $\mathrm{mm} /$ year per decade in the central U.S. In the absence of near-term climate change mitigation, projections indicate higher frequencies of extreme heat events, more intense droughts, greater precipitation variability, fewer frost days, and increases in heavy precipitation events (Romero-Lankao et al. [43]). Although there is large spatial variability of climate change impacts (and variation in confidence among climate change models), it is becoming clearer that corn farming in the highly-productive, central U.S. will need to adapt to an evolving production environment. The full range of climate adaptation strategies is unknown and cannot be forecast, but agricultural adaptation is not a new phenomenon. Agricultural technology and best management practices have been continually adapting and advancing over much of the last century (Schimmelpfennig et al. [45]; Zilberman et al. [54]). Continued adaption will likely involve R\&D by bio- and information-technology firms and public research institutions (Heisey and Day-Rubinstein [18]), and marginal adjustments of inputs and cropping patterns at the farm level (Marshall et al. [27]). Both input and output adjustments on farms and R\&D adjustments in industry and research institutions will also be influenced by agricultural policy as it adjusts to changing climatic and production environments.

Corn production, and corn yields in particular, result from significant interdependence between climate, information technologies, and biotechnologies in the near term. To capture the main aspects of dynamic corn production, we estimate Bayesian dynamic regressions using temporal variation in yields and weather over 1960-2011. Our Bayesian dynamic regressions improve on more conventional agricultural econometric methods by directly modeling outliers, structural change, yield skewness, and limited information content of older data. Our research examines four hypotheses: (i) corn yield growth has occurred over the past half-century despite climate change, (ii) future climate change impacts on yields will exhibit substantial state and regional variability, (iii) extreme weather, especially intense precipitation, has had negative effects on yields, and (iv) precipitation and nitrogen interact in determining yields. 
We fit two competing regression specifications: one that incorporates average temperature and precipitation, and another that incorporates weather extremes. Coefficients are used to forecast yields in 2012-2031 for the 11 highest corn-producing states. We compare forecasts across three yield distribution assumptions: normal (using least squares), Student's $t$, and beta.

The balance of the paper proceeds as follows. Section 2 examines the related literature on climate change, bio- and information technologies, and corn yields. Section 3 lays out the econometric model and two estimation procedures. Section 4 presents both regression specifications and examines the in-sample and out-of-sample data. Section 5 provides our empirical results. Section 6 discusses the results and conjectures about the future of US corn yields, and Sect. 7 concludes. All tables and figures of results are contained in the appendix.

\section{Corn Yields, Biotechnologies, and Climate Change}

The present research stems from McFadden and Miranowski [29]. Using Bayesian dynamic models for the top 11 producing states, we found that Corn Belt corn yields will grow by $28-33 \%$ through 2031, with increases in Great Lakes states' yields up to $37 \%$. Yield growth in the Great Plains states is less pronounced, and in certain lessproductive areas, yields may decline. In states more suited to growing corn, nitrogen applications can partially mitigate harmful impacts of heavy precipitation. Regarding model fit, we found that regression models with $t$-distributed and beta-distributed yields have similar in-sample performance. McFadden and Miranowski [30] had a similar focus. Using data on 770 rainfed counties in 14 states, we confirmed that yields will increase by $10-40 \%$ over the next two decades. Long differences in weather variables are used to identify a long-run, cross-sectional relationship between climate change and technical progress in yields. After controlling for regional soil productivity and other possible confounds, we found that technical change in yields responds endogenously to climate change in the long run.

There is a large literature on the agricultural economics of bio- and information technologies. U.S. farm-level adoption of biotech corn has been rapid, driven by expectations of higher yields and input savings (Fernandez-Cornejo and Caswell [11]). This has led to changes in the nature of seeds research and the mix of public and private breeding research, with market structure implications for corn and soybeans (Foltz et al. [15]; Shi [47]; Shi et al. [48]; Huffman [23]). The increased potential for much higher yields has also expanded domestic biofuels markets and helped initiate advanced biofuels, though there is uncertainty surrounding biofuels policy (de Gorter and Just [8]; Miranowski [36] Rosburg et al. [44]). Consumer acceptance of biotech foods has been increasing in recent years (with notable exceptions among some market groups), with information effects and labeling having important roles in shaping consumer willingness-to-pay (Huffman et al. [22]; McFadden and Huffman [28]; McFadden and Huffman [33]).

Much less is known empirically about the range of adaptation mechanisms available to farms and their optimal uses under adverse weather conditions. In principle, 
farmers may move spring plantings forward to take advantage of warmer early-season temperatures and avoid late-season extreme heat (Ortiz-Bobea and Just [39]). The effectiveness of this strategy, however, could be limited by greater variability in frost days and distributional shifts in precipitation across the growing season.

Marginal adjustments in the timing and volume of irrigation water applications, where available, is another plausible adjustment strategy. Hornbeck and Keskin [21] show that farmers in the Great Plains substituted toward more water-intensive crops as irrigation water from the Ogallala Aquifer became available. In a similar study, Hendricks and Peterson [19] estimate that the demand elasticity for irrigation water in this region is very inelastic, so marginal adjustments in the near term seem likely. Over the long run, dwindling aquifer recharge rates could shift irrigated corn production to regions with more sustainable irrigation or rainfed regions (Marshall et al. [27]).

McFadden and Miranowski [31] address intensive and extensive margin adaptation to climate using data from several thousand farms in the central U.S. We find that early- and late-season temperatures and rainfall influence the selection or choice to grow corn. Mid-season weather patterns influence the choice of growing soybeans. Yet, crop switching, which may occur under mild climate change scenarios, is far more influenced by soil productivity. In other words, the choice of growing corn, soybeans, and other crops is driven more by soil productivity factors than mild climate change adjustments.

Our research fits more generally in the economics of agricultural yields. These studies vary with respect to forecasting, in-sample weather impacts, and distributional form. Miranowski et al. [35] use data on the top 17 corn-producing states during 1960-2011 for forecasting. There is evidence of at least one structural break in each state, and linear trend and autoregressive models are estimated around these breaks. Corn yield forecasts indicate increases of 1-4 bu/ac per year through 2030, depending on the presence of short- or long-run trends.

Regarding weather and yields, several studies underscore the importance of changing weather patterns and biotech adoption rates for in-sample studies (Schlenker and Roberts [46]; Roberts et al. [42]; and Xu et al. [52]). The emphasis has been mainly on temperature-related variables (e.g., growing degree days) and drought indicators. More statistical approaches have been implemented by Harri et al. [17] and Claassen and Just [4]. These studies find evidence of yield skewness and other factors contributing to non-normality that vary over growing regions. The most suitable distributions for modeling yields remains an open question.

\section{Econometric Model}

We begin by estimating all regression models with ordinary least squares (OLS). These estimates provide a useful benchmark for comparisons among the two dynamic models explained below. Assuming normally-distributed yields, differences between least squares and the dynamic $t$-distribution results primarily reflect the differences between static and dynamic estimation methods. 


\subsection{Dynamic Bayesian Regressions}

The first dynamic framework is a linear state space model. State space models have an observation equation and a state equation. The dependent variable at any time period is a linear function of unobserved states and a random disturbance. The law of motion for unobserved states is a random walk. We estimate the following system:

$$
\begin{gathered}
Y_{t}=\mathbf{F}_{t}^{T} \boldsymbol{\theta}_{t}+v_{t}, \quad v_{t} \sim N\left(0, k_{t} \phi_{t}^{-1}\right) \\
\boldsymbol{\theta}_{t}=\mathbf{G}_{t} \theta_{t-1}+\boldsymbol{\omega}_{t}, \quad \boldsymbol{\omega}_{t} \sim t_{n_{t-1}}\left(\mathbf{0}, \mathbf{W}_{t}\right) .
\end{gathered}
$$

In period $t, Y_{t}$ is the dependent variable, $\mathbf{F}_{t}^{T}$ is a $(1 \times n)$ vector of regressors, $\boldsymbol{\theta}_{t}$ is an $(n \times 1)$ vector of regression coefficients (state parameters), $\mathbf{G}_{t}$ is the system evolution matrix, $v_{t}$ is the observation error, and $\omega_{t}$ is the system disturbance vector. Note that (1) is the observation equation, and (2) is the state evolution equation. Error terms satisfy temporal and mutual independence: $\operatorname{Cov}\left(v_{s}, v_{t}\right)=0, \operatorname{Cov}\left(\boldsymbol{\omega}_{s}, \boldsymbol{\omega}_{t}\right)=\mathbf{0}_{n \times n}$ for all $t \neq s$, and $\operatorname{Cov}\left(v_{s}, \omega_{t}\right)=\mathbf{0}_{n}$ for all $t, s$. The observation variance is the product of a known variance dispersion parameter, $k_{t}$, and $\phi_{t}$, the observation's precision, which has a gamma prior distribution. The system disturbance is from a mean-zero, multivariate $t$-distribution with degrees of freedom that are updated sequentially and a block-diagonal variance (scale matrix), $\mathbf{W}_{t}$. The three submatrices comprising $\mathbf{W}_{t}$ are an intercept block, a regression block, and a time trend block. Explanatory information decays at different rates, so each of the blocks is adjusted by a separate discount factor: $\delta_{i n t}, \delta_{R}$, and $\delta_{t r}$, respectively.

Priors on coefficients and the observation variance are the following:

$$
\begin{gathered}
\theta_{t} \mid I_{t-1} \sim t_{\delta_{t} n_{t-1}}\left(\boldsymbol{\alpha}_{t}, \mathbf{R}_{t}\right) \\
\phi_{t} \mid I_{t-1} \sim \Gamma\left(\frac{\delta_{t} n_{t-1}}{2}, \frac{\delta_{t} d_{t-1}}{2}\right),
\end{gathered}
$$

where $\boldsymbol{\alpha}_{t}$ and $\mathbf{R}_{t}$ are the location and scale parameters, respectively, of the multivariate $t$-distribution with $\delta_{t} n_{t-1}$ degrees of freedom. The shape and scale parameters of the gamma distribution are $\left(\delta_{t} n_{t-1} / 2, \delta_{t} d_{t-1} / 2\right)$, respectively. Knowledge available at time $t-1$ is contained in the information set, $I_{t-1}$. The discount factor here, $\delta_{t}$, is a general discount and is set very close to unity, e.g., 0.99.

The posterior distributions and one-step ahead forecasts are:

$$
\begin{aligned}
\boldsymbol{\theta}_{t} \mid I_{t} & \sim t_{n_{t}}\left(\mathbf{m}_{\mathbf{t}}, \mathbf{C}_{t}\right) \\
\phi_{t} \mid I_{t} & \sim \Gamma\left(\frac{n_{t}}{2}, \frac{d_{t}}{2}\right) \\
Y_{t} \mid I_{t-1} & \sim t_{\delta_{t} n_{t-1}}\left(f_{t}, Q_{t}\right) .
\end{aligned}
$$


Although the dependent variable depends linearly on regression coefficients, the system of recursive equations used for estimation involve several nonlinearities affecting posterior distributions. Note that $k$-step ahead forecast distributions are updated similarly. See Pole et al. [41], West and Harrison [51], and Durbin and Koopman [9] for more details.

\subsection{Time-Varying Beta Distributions}

The thick-tailed $t$-distributions in dynamic linear models (DLMs) are beneficial for modeling outliers, but one drawback is their symmetry. For several U.S. states, high yields occur frequently and low yields infrequently, suggesting that conditional distributions should be negatively skewed. ${ }^{1}$ The beta distribution permits flexibility in modeling skewed yields (Day [7]; Claassen and Just [4]). The support of the beta distribution is $[0,1]$. We use a four-parameter transformation in which each state's yield at time $t$ is $\left(y_{t}-\max \right) /(\max -\min )$, where $\max$ and $\min$ are state-specific maximum and minimum obtainable yields. ${ }^{2}$

The time-varying beta model builds on da Silva et al. [6] and Lopes and Tsay [26]:

$$
\begin{gathered}
Y_{t} \mid \mu_{t} \sim \operatorname{Beta}\left(\phi \mu_{t}, \phi\left(1-\mu_{t}\right)\right) \\
\mu_{t}=\left(1+\exp \left[-\boldsymbol{\beta}_{t} \mathbf{x}_{t}\right]\right)^{-1} \\
\boldsymbol{\beta}_{t} \mid \boldsymbol{\beta}_{t-1}, \mathbf{W} \sim N\left(\boldsymbol{\beta}_{t-1}, \mathbf{W}\right) .
\end{gathered}
$$

The system moves according to (10), in which the states, $\boldsymbol{\beta}_{t}$, are given independent normal distributions with means $\boldsymbol{\beta}_{t-1}$. The beta distribution is a member of the exponential family of distributions, and (9) links the states and regressors, $\mathbf{x}_{t}$, to the dependent variable's mean, $\mu_{t}$. The time-invariant precision parameter, $\phi$, is inversely related to the dependent variable's variance, $\mu_{t}\left(1-\mu_{t}\right) /(1+\phi)$.

We use the Liu and West [24] particle filter to estimate (8)-(10). Readers interested in the exact details of this algorithm or similar sequential Markov Chain Monte Carlo methods are referred to Durbin and Koopman [9], Liu and West [24], and Migon et al. [34]. We first specify priors: $\phi \sim \operatorname{Inv} \Gamma\left(\alpha_{p}, \beta_{p}\right)$, and distinct $W \sim \operatorname{Inv} \Gamma\left(\alpha_{w}, \beta_{w}\right)$

\footnotetext{
${ }^{1}$ We analyze quantile-quantile (QQ) plots of OLS residuals for various regression specifications across U.S. states. The plots indicate substantial skewness for certain states. We also undertake Shapiro-Wilk tests of normality and Kolmogorov-Smirnov tests that the errors come from a beta $(5,2)$ distribution. A skewed distribution is more appropriate for some states, but we cannot reject the null hypothesis of normality for five states.

${ }^{2}$ Several techniques can be used to estimate the four parameters of the reparameterized beta distribution. We impose minimum and maximum yields proportional to each state's observed minimum and maximum. Specifically, maximums are set at $150 \%$ of observed, state-specific maximums, while minimums are set at five bushels fewer than the smallest observed yields.
} 
and $\beta_{0} \sim N\left(m_{0}, C_{0}\right)$ priors for each entry of the initial $\boldsymbol{\beta}$. The hyperparameters are $m_{0}=0, \alpha_{p}=20, \beta_{p}=315$, and $C_{0}=0.3$. For $W$ corresponding to the first component of $\boldsymbol{\beta}, \alpha_{w}=3$ and $\beta_{w}=0.2$. For all other entries of $\boldsymbol{\beta}$, we increase $\alpha_{w}$ by 0.1 with corresponding $\beta_{w}=\left(\alpha_{w}+1\right) 0.05$. There is a tuning parameter in the model, which is set to 0.97 and consistent with a discount factor of roughly 0.95 . To forecast, we first simulate the states from (10), taking medians across all replications of sequences. These simulated values are then inserted into (9), as well as the weather regressors. The last available estimate of $\phi$ at $t=2011$ is used for all forecasts.

\section{Regression Specifications and Data}

Prior to estimation of both regression specifications given below, we estimate a specification containing only an intercept and linear time trend. They are denoted below as "trend only". This is designed to illustrate potential forecast biases from models that do not account for a crucial component of agricultural production (e.g., exogenous weather).

\subsection{Baseline Specification}

Agricultural economics and agronomy suggest a basic regression model that uses temperature and precipitation variables during important periods of the growing season to explain yields. To identify the effects during important growth stages, we use statewide means of precipitation and temperature for the months of May, June, July, and August. Our sample for 1960-2011 is composed of the top 11 cornproducing states for 2011 (producing $2 \%$ or more of U.S. production). Gridded monthly averages of daily data are from the National Oceanic and Atmospheric Administration's (NOAA) U.S. Climate Divisional Database. A linear time trend is used to detrend yields. For the $j^{\text {th }}$ state in period $t$, the baseline specification is:

$$
\mathbf{F}_{j, t}^{T}=\left(1 \text { MonthlyTemp }_{j, t} \text { MonthlyPrec }_{j, t}\left(\operatorname{JulyPrec}_{j, t}\right)\left(N_{j, t}\right) T\right)
$$

The $\left(\right.$ July Prec $\left._{j, t}\right)\left(N_{j, t}\right)$ term captures the interaction of July rainfall and nitrogen. ${ }^{3}$ After estimation, highest posterior density (HPD)-based tests help reduce the model to a subset of important variables. The statistic is compared at each time point

\footnotetext{
${ }^{3}$ Nitrogen use data are from the Economic Research Service (ERS) of the United States Department of Agriculture (USDA). There are missing data in all states for certain years. We use zero-intercept regressions of state-level nitrogen use on total U.S. nitrogen use to impute the missing values. The nitrogen categories included are anhydrous ammonia, ammonium nitrate, ammonium sulfate, nitrogen solutions, and urea. Nitrogen forecasts for 2013-2031 are obtained by OLS regression on time.
} 
to the $95 \%$ critical value of the $F$ distribution. If the critical value is exceeded for approximately $30 \%$ of the 52 years in our sample, we include the regressor. ${ }^{4}$

\subsection{Alternative Specification}

A drawback of the baseline model is its simplification of more complex biological relationships, especially regarding extreme weather. To incorporate some of these effects, researchers have proposed Growing Degree Days (GDD), Heating Degree Days (HDD), Extreme Degree Days (EDD), Killing Degree Days (KDD), and other transformations of temperatures that account for accumulated beneficial or extreme sunlight. In addition, diurnal temperature range (DTR), the difference between the daily maximum and minimum temperatures, is used to measure overnight plant cooling.

For transparency, we capture temperature extremes by indicators of a monthly average maximum temperature equaling or exceeding $90^{\circ} \mathrm{F}$ in July and August (denoted below as JulH and AugH). ${ }^{5}$ In several sample states, the corn plant begins to pollinate and develop kernels during July and August growth stages that are sensitive to weather extremes. The two dummy variables rely on data from NOAA's Global Historical Climatology Network (GHCN), which are station-level data of monthly means from daily maximum and minimum temperatures. We also use July and August DTR, with data again from GHCN.

High rainfall rates can lower yields by leaching plant nutrients in soils. Rainfall runoff and erosion can transport nutrients on and bound to the soil surface and limit fertilizer effectiveness. Rainfall intensity is measured by counts from weather stations receiving at least one inch of rain per hour, similar to daily heavy precipitation events previously tracked by EPA [10]. Counts of hourly rainfall events are constructed from hourly, station-level data in NOAA's Cooperative Observer Network (COOP). ${ }^{6}$ There are very few sources providing forecasts of extreme rainfall events (Groisman et al. [16]). We use negative binomial regressions on time to generate forecasts. ${ }^{7}$ The alternative specification for the $j^{\text {th }}$ state in period $t$ is:

\footnotetext{
${ }^{4}$ This relative frequency criterion is robust to selecting other threshold values. Individual $t$ - and joint tests from state-level OLS estimation agree with our HPD-based tests for a majority of regressors across states.

${ }^{5}$ This cutoff is a compromise between the $86^{\circ} \mathrm{F}$ used in canonical GDD formulas and Lobell et al. [25], the $84.2^{\circ} \mathrm{F}$ suggested by Schlenker and Roberts [46], and the $90^{\circ} \mathrm{F}$ of Xu et al. [52]'s excess heat degree days.

${ }^{6}$ No cooperative has a complete data record. Missing data could be imputed based on neighboring data, but this could worsen measurement error. Heavy rainfall events occur during thunderstorms, which NOAA [38] suggests average 15 miles in diameter with 30-minute lengths. The typical closest station is 5-10 miles away from the observing station, where rainfall rates could significantly differ. ${ }^{7}$ Likelihood ratio tests reject the null hypothesis of equidispersion, assumed in Poisson regression models. Estimates from the Poisson and negative binomial regressions are very similar and do not alter the forecasts.
} 


$$
\begin{gathered}
\mathbf{F}_{j, t}^{T}=\left(1 \text { JulyDT }_{j, t} \text { AugDT }_{j, t} \text { July }_{j, t} \text { Aug } H_{j, t}\right. \\
\text { RainEvent } \left._{j, t}\left(\text { JulyEvent }_{j, t}\right)\left(N_{j, t}\right) T\right)
\end{gathered}
$$

where RainEvent ${ }_{j, t}$ are separate counts of heavy rainfall events for May, June, July, and August. We do not develop a reduced model. Distinct from the baseline model, the nitrogen interaction uses July rainfall events.

\subsection{Climate Change Scenarios}

Given the evidence that current weather conditions reflects global warming, future weather patterns will not be similar to those during 1960-2011. Using the in-sample weather variables for forecasting is thus unsuitable. One common practice is to assimilate output from multiple realizations of one or more global climate models (GCMs). There are drawbacks (e.g., differing GCM assumptions and conflicting GCM results), but this practice is reasonable for our purposes (Auffhammer et al. [1]).

Data on precipitation, average surface temperatures, and minimum and maximum daily temperatures for the next two decades (2012-2031) are taken from the World Climate Research Programme's (WCRP) Coupled Model Intercomparison Project phase 5 (CMIP5), available from the Bureau of Reclamation, Department of the Interior [3]. These GCMs have been downscaled to $1 / 8^{\circ}$ resolutions and adjusted for mismatches between simulations and the historical record. The output is classified according to four "levels" of climate change. ${ }^{8}$ Results in the next section only consider mild climate change, i.e., RCP 2.6. Estimates and forecasts under severe climate change, RCP 8.5, are very similar to the RCP 2.6 results. This is because significant departures from current weather patterns are not projected for the next two decades.

Climate projection data are available by latitude and longitude. To ensure that the projections are not influenced by a few GCMs or specific runs of a particular GCM, we average over several models, some with multiple runs. ${ }^{9}$ Our choice of models is guided by Pierce et al. [40], which gives a ranking of "high skill" models.

\footnotetext{
${ }^{8}$ These four levels are representative concentration pathways (RCP) 2.6, 4.5, 6.0, and 8.5. The pathways index radiative forcing, the rate of change in the difference between incoming and outgoing solar energy in the atmosphere. Larger radiative forcing indicates more severe climate change.

${ }^{9}$ Averages are taken over 13 GCMs: CanESM2, CCSM4, GFDL-CM3, GFDL-ESM2G, GFDLESM2M, GISS-E2-R, HadGEM2-AO, HadGEM2-ES, MIROC-ESM, MIROC-ESM-CHEM, MIROC5, MPI-ESM-MR, and MPI-ESM-LR (Reclamation [3]).
} 


\subsection{Descriptive Statistics}

Table 1 contains descriptive statistics for the baseline model in our 11-state sample for 1960-2011. Early-season temperatures range in $54-64^{\circ} \mathrm{F}$, while temperatures in June, July, and August are in $64-79^{\circ} \mathrm{F}$. The hottest month, July, is also the month with the lowest variability in temperatures. Similarly, May experiences the lowest average temperatures but exhibits the largest standard deviations. On average, the warmest state is Kansas, with monthly average temperatures near $80^{\circ} \mathrm{F}$. Michigan is the coldest state but exhibits the most stability in (relatively low) average rainfall, 3.1-3.4 in. per month in the growing season. The traditional Corn Belt states of Iowa, Illinois, and Indiana have abundant monthly rainfall, 3.6-4.8 in. South Dakota is a perennially dry state, averaging roughly 2 inches in August.

Descriptive statistics for regressors in the alternative specification are given in Table 2. The Corn Belt states of Iowa, Illinois, and Indiana have had the lowest average monthly DTR, $21-22^{\circ} \mathrm{F}$. This contrasts with warmer and drier states, such as South Dakota and Kansas, which have the largest DTR. Both of these states also have many occurrences of hot monthly average maximum temperatures in July and August. $85 \%$ of the July months in Kansas during 1960-2011 have experienced average maximum temperatures exceeding $90^{\circ} \mathrm{F}$. Only $17 \%$ of July months for Illinois and $48 \%$ for Nebraska have had similar temperature effects. Missouri, Iowa, and Illinois have relatively high counts of intense hourly rainfall, while Michigan and South Dakota have lower instances of intense hourly rainfall. This pattern is evidenced in the average precipitation statistics of Table 1. Intense rainfall is concentrated in June and July, months in which there are higher frequencies of storms and thunderstorms.

\section{Empirical Results}

Figure 1 depicts forecast means and 95\% credible intervals over 2012-2031 in the baseline dynamic linear model for Iowa and Illinois. ${ }^{10}$ Both states begin in 2012 at very similar points, 160-170 bu/ac, but evolve differently over the forecasting window. Means increase roughly linearly over the 20 years by $2-5 \mathrm{bu} / \mathrm{ac}$ for Iowa and $1-8 \mathrm{bu} / \mathrm{ac}$ for Illinois. The mean gap between states is small for all years and does not exceed 15-20 bu/ac, which replicates the pattern observed in most years in the data. This is a consequence of similar weather, soil productivity, management techniques, and cropping patterns for Iowa and Illinois in recent years. Iowa's forecasted 2031 mean is 219 bu/ac, a $27 \%$ increase over 2011 yields, whereas Illinois' mean is 206 bu/ac, a $31 \%$ increase over 2011 yields. Robust yield growth is similar for other Corn Belt states in our study and compares well with the county-level results in other studies (Xu et al. [52]; McFadden and Miranowski [29]). The most noticeable difference between forecasts is the substantial uncertainty in Illinois yield growth.

\footnotetext{
${ }^{10}$ For space considerations, we have narrowed the focus of our discussion. Results for all states are available upon request. Similar state-level results are obtained in McFadden and Miranowski [30].
} 
The $95 \%$ credible region for Iowa yields in 2031 is $[185,250]$ bu/ac, but we cannot rule out slight declines in Illinois yields over the next decades. ${ }^{11}$

We next turn to a comparison of forecasts for two Great Lakes states, Minnesota and Wisconsin, in Fig. 2. Minnesota and Wisconsin are interesting to consider because of similarities in weather but large discrepancies in soil productivity and management practices. As with the Corn Belt states, Minnesota and Wisconsin begin similarly at $170 \mathrm{bu} / \mathrm{ac}$ but then have overlapping forecast means throughout the remainder of the two decades. In 2031, forecast means are 217-220 bu/ac, representing $41 \%$ and 39\% increases on 2011 yields in Minnesota and Wisconsin, respectively. Unlike estimates for other regions, forecasts for Great Lakes states are smoother and more linear. This is a consequence of smooth climate model projections for average temperature and precipitation in more northern latitudes. Moreover, Great Lakes states have experienced milder temperatures and less variable rainfall historically, which is reflected in regression slopes that permit greater yield growth. However, we forecast much higher yield variability for Wisconsin over the next several years, with equal possibilities of greatly-increasing or slightly-declining yields. The relatively large variances for Illinois and Wisconsin could be partially driven by lake-effect weather patterns associated with proximity to Lakes Superior and Michigan.

The forecasts for Nebraska and Kansas in Fig. 3 stand out from those of other highly-productive states for several reasons. Nebraska's yield growth is similar to that of Iowa and Minnesota. Average yields increase 38\% from the 2011 level of $160 \mathrm{bu} / \mathrm{ac}$ to the 2031 level of $221 \mathrm{bu} / \mathrm{ac}$. Among Corn Belt states, Nebraska exhibits much less forecast uncertainty, with narrow credible regions that extend 15-20 bu/ac about the mean. Corn production in western Nebraska relies on aquifer irrigation, while crops in eastern Nebraska are either rainfed or rainfed with supplemental irrigation from nearby river water. In recent years, Nebraska yields have been more stable than in other Corn Belt states, in part because of unique weather and sufficient supplies of groundwater irrigation. This is in sharp contrast to Kansas. Our forecasts indicate a gradual decrease in yields over the coming years but with much year-toyear variation. In the last three years of the sample, Kansas yields declined $31 \%$ from $155 \mathrm{bu} / \mathrm{ac}$ in 2009 to $107 \mathrm{bu} / \mathrm{ac}$ in 2011. This marked yield decrease is incorporated in our models' dynamic updating and provides forecasts that are less optimistic than static models, e.g., least squares. To the extent that adverse weather and dwindling irrigation inputs partially caused the recent yield decline and will persist or increase in the near future, the dynamic forecast means will perform better than the least squares forecasts. ${ }^{12}$

To illustrate the model dynamics underlying our baseline forecasts, estimated coefficients for the July rainfall-nitrogen interaction in Iowa are provided in Fig. 4. We choose to illustrate coefficients for the time-varying beta model because the

\footnotetext{
${ }^{11}$ The model-selected discount rate for Illinois is 0.90 , which partially contributes to a large variance. In general, the short-run yield-growth trend in Illinois is larger than its long-run average trend, in agreement with the Illinois results in Miranowski et al. [35].

${ }^{12}$ Forecasts for several rainfed counties in Kansas are also largely declining through 2031 (McFadden and Miranowski [29]). This suggests that much warmer and drier weather is an important concern for areas that cannot use irrigation for mitigation.
} 
scaling is more straightforward to interpret. The figure shows that rainfall-nitrogen interactions have evolved stably over time. At the beginning of our sample, the interaction effects first increase and then moderately decrease, but there are no abrupt breaks in the movement of the estimates. This supports our use of dynamicallyupdated models for forecasting. The marginal impacts of nitrogen, evaluated at the in-sample July rainfall data, have nonlinear effects. This is because the marginal impact is a nonlinear (logistic) function of variable July rainfall and all other weather regressors. Averaged over 1960-2011, the marginal impact of the nitrogen interaction is $0.53 \mathrm{bu} / \mathrm{ac}$. Nitrogen availability generally enhances the marginal productivity of July precipitation, which improves pollination and corn ear fruiting. In other words, adequate July precipitation improves the marginal productivity of nitrogen applied in the growing season.

Evolution in the July rainfall event-nitrogen interaction from Iowa's alternative specification, shown in Fig. 5, differs from that in the baseline specification for several key reasons. Noticeable jumps in the coefficients occur over several years. There is a downward trend during 1967-1969 and then a distinct one-time drop in 1983, consistent with evidence of breaks in past research (McFadden and Miranowski [30]; Miranowski et al. [35]). ${ }^{13}$ Given the widespread drought in mid-1983, a substantial drop in coefficients involving summer precipitation is intuitive and expected. There is also a pronounced downward trend near the sample endpoint, with a modest uptick in 2011. This is the result of improved nitrogen use efficiency in recent years and a relatively lower number of intense hourly rain events in Iowa during July 2011. Similar to the baseline estimates, the interaction effect has an average positive marginal impact on yields. However, our ability to give more precise conclusions is limited by the wider $95 \%$ credible intervals.

Model performance is assessed in Table 3 using a mean absolute deviation (MAD) criterion. We average the absolute value of the difference in forecasted and actual yields over 2012-2014. These are calculated for the three models (OLS, dynamic $t$-distribution, and dynamic beta distribution) and three specifications (trend-only, baseline, and alternative regressors). For Iowa, Nebraska, and Minnesota, three of the top four producing states, the OLS model with the baseline regressors has the highest out-of-sample forecast accuracy. These three states experienced prolonged drought and episodes of high heat during 2012 and 2013 that reduced yields from recent upward trends. However, most models perform similarly well, especially the $t$-distributions for Iowa and Nebraska and the beta distributions for Minnesota. The difference between these forecasts and those of the best models is $1-4 \mathrm{bu} / \mathrm{ac}$.

Several other interesting features can be inferred from Table 3. First, practical differences in forecast accuracy between static and dynamic models are illustrated in several states. For example, the best performing model for Illinois is a trend-only dynamic $t$-distribution, though none of the models are highly accurate. Illinois 2014 yields reached a record high of $200 \mathrm{bu} / \mathrm{ac}$, roughly $27 \%$ over its $157 \mathrm{bu} / \mathrm{ac}$ average in 2011 and a $90 \%$ increase on its 2012 yields of $105 \mathrm{bu} / \mathrm{ac}$. This validates a basic tenet of

\footnotetext{
${ }^{13}$ Bayesian model monitoring based on cumulative sum (CUSUM) techniques suggest a cumulative breakdown of model fit in several years, including 1983.
} 
forecasting: no plausible models can reliably forecast highly-erratic time series over long time periods. However, our dynamic Bayesian methods perform better because of the underlying updating procedures. This is also confirmed for Michigan, where yields moved slowly upward over 2007-2011. Static methods underestimate more recent yield growth because of flatter regression slopes needed to accommodate early, less-informative data. Second, models that account for weather extremes forecast better in states where these have occurred more frequently and are more likely to occur in the future. Forecasts from the alternative beta distribution matched poor yields in Kansas in 2012 and 2013 much better than the optimistic OLS forecasts. In South Dakota, a relatively warm and dry state, the best model is the alternative dynamic $t$-distribution. Note that for these states, temperatures above $90^{\circ} \mathrm{F}$ tend to decrease yields, but intense hourly precipitation can boost yields in particularly dry years. Third, several highly-productive regions with milder weather do best under the baseline beta-distributed model. This is intuitive for the eastern Corn Belt states of Indiana and Ohio. Ample rainfall and cooler growing seasons point to the baseline beta model as a reasonable choice and is confirmed by the lowest deviations, 31.3 and $13.7 \mathrm{bu} / \mathrm{ac}$, respectively.

In sum, our results indicate significant yield growth over the past half century and into the twenty-first century in the face of substantial climate change. Although intense precipitation reduces yields, mean precipitation and nitrogen applications interact in raising or lowering yields, depending on the limiting factor. A critical dimension of our analysis is the geographic variability in climate change impacts, as indicated by our state-by-state comparisons in Figs. 1, 2 and 3. Climate change will have important regional impacts based on soil productivity, management practices, and geographical features contributing to distinct weather patterns. Our state-level results are an informative approach for comparing impact magnitudes among neighboring (or otherwise similar) states. In this sense, the results are in broad agreement with economic theory emphasizing the geographic distribution of impacts (Zilberman et al. [53]).

\section{Discussion}

Our dynamic estimates and forecasts have several policy and adaptation implications for an increasingly-dynamic production environment. A crucial feature of rising yields has been soil productivity and conservation. Successful adaptation to a changing climate requires improved information about soil management practices in changing production environments. Additionally, we should recognize important soil productivity limitations in a changed climate. Our state-specific regressions incorporate soil productivity, and productivity of other inputs, indirectly in the intercepts. Although soil organic matter may fluctuate slightly across years depending on cropping choices and practices, inherent soil productivity is largely time-invariant if sound soil conservation is practiced. This could restrict the potential to shift corn production into regions with more advantageous climates, and at the same time 
sustain higher yields if inherent soil productivity is limited, i.e., soil is only productive if timely moisture and favorable temperatures are available. In other words, soils and weather are both limiting factors in production. This generates an important soil productivity-climate tradeoff that should be considered in farmers' dynamic economic decision making (McFadden and Miranowski [31]). In upcoming decades, Minnesota, Michigan, and Wisconsin will likely experience a comparative advantage in beneficial climate, but this will be offset by poorer soil productivity in many areas or states, particularly in Wisconsin and Michigan. More generally, the sandier soils of the Great Lakes regions and the clay-dominant soils of the Southern Plains are not ideal soil structures for commercial corn growing. To the extent that our models are capturing poorer soil productivity with smaller intercept coefficients, production shifts to more northern latitude states are viable adaptation options but not viable economic options.

The dynamic interdependence between climate change and irrigation water availability is another crucial component of our analysis. Withdrawal rates of Ogallala Aquifer water have exceeded recharge rates in some areas south of Nebraska. In response to rising water costs and reduced availability, many irrigated operations in this region have gradually curtailed or ceased irrigation water applications. Given the lack of competitive sources of water, this outcome likely contributes to sizeable yield forecast divergence for Nebraska and Kansas in Fig. 3. The extent to which advanced information systems will alter the relationship between irrigation, weather, and other inputs is a similarly important issue.

The dynamics of corn production in recent years have been influenced by innovative adaptation strategies that rely on more computer-based monitoring and measurement data and management systems. In an era of knowledge technology and big data systems, many agricultural supply industries are working together to develop knowledge-based systems to facilitate farmers' adaptation of crop management decisions to climate change. These firms are developing climate-focused technologies for farmers, collecting extensive production data, monitoring weather and growing conditions, and providing real-time management recommendations on fertility, planting, pest control, and harvest activities. At the core of these technologies are networks of sensors and monitors providing near-time weather forecasts and improved information to farmers. Pending government approval, unmanned aerial vehicles will be used for scouting and monitoring nutrient, pest, and crop conditions and directing applications where needed.

Other closely-related adaptation strategies include adoption of precision and prescription agricultural innovations. Increasing seed industry concentration has boosted R\&D for seed-based technologies with substantial weather and climate interactions. Field trials for drought-tolerant corn indicate significant opportunities for limiting downside risk of drought and heat spells. One source of complication, though, is a yield penalty incurred under excessive rainfall in possible inundation conditions, especially during certain stages of plant growth. Modern plant breeding is using bioin- 
formatics to rapidly select for traits from existing corn seed lines to design plants appropriate to field conditions, i.e., and developing prescriptions to optimize yields. Combined with wireless communication, GPS guidance, and variable rate applicators, the result is a more automated system that increases yields, lowers energy and seed costs, and reduces the likelihood of pest infestations. However, adoption of these technologies may depend to some extent on the evolution of agricultural policy.

U.S. government policy has, at times, significantly influenced the price, location, crop mix, and acreage of agricultural production, especially in corn. USDA has been looking into the dynamic relationships between climate change and corn production for many decades. Impact assessments and steps toward greater climate change preparedness are summarized in its national climate change adaptation plan (USDA [50]). Conservation policies may need revision over space and time as intensity and quantity of rainfall and temperature change. Given increased potential for soil erosion from intensifying precipitation, conservation practices may need to be revised from using the universal soil loss (USLE2) base to reducing peak soil loss. From a water quality standpoint, intense rainfall events may increase nutrients being flushed from tile drainage and call for innovative drainage management strategies. EPA may have to revise point source pollution guidelines for animal feeding operations especially with increasing intense rainfall.

The 2014 Farm Act is shifting emphasis toward increased insurance and risk management strategies relative to traditional program payments and conservation incentives. Although risk is likely to increase with extreme weather, so is the need for conservation incentives to offset soil, nutrient, pest resistance, and productivity losses as well as water quality deterioration. USDA's Risk Management Agency (RMA) paid nearly $\$ 12$ billion in losses from adverse weather in 2013. Under increasing likelihood of climate-induced losses, RMA's total annual indemnity payments may increase. Over the long run, innovations in insurance products and non-insurance risk management tools may be needed to limit large increases in weather-related risk and the associated budget exposure. This may entail partnerships between RMA and private firms to design more information-based and climate-focused risk reduction tools. There have already been recent innovations in climate-focused insurance products that are likely to continue as yield volatility increases with changing climate.

\section{Conclusion}

We have now entered a new era of knowledge-based information management systems. Biotechnology is an integral and necessary part of these knowledge-based systems which involve complementary information technologies, precision monitoring and farming practices, utilization of big data, bioinformatics in seed selection and development, prescription agriculture, and knowledge-based management systems to assist in adjusting and adapting to more extreme weather. Agronomists 
attribute yield growth to genetic potential of a variety, environmental factors, and crop management, as well as the interaction of these factors. Much of corn yield growth, roughly 60-80\%, is attributed to improved genetics or crop breeding (Smith et al. [49]; Crosbie et al. [5]). Information and other knowledge technologies provide an opportunity to enhance the contribution of management to corn yield growth. As Smith et al. [49]) state, "More effective use of genetic diversity and crop management will allow U.S. maize breeders and farmers to accommodate climate change for the foreseeable future." What is happening in corn production parallels what occurred in poultry, pork, and dairy livestock production, as discussed in Hennessy et al. [20]. We are rapidly moving from "attentive husbandry or management" to "knowledge husbandry or management" by corn and other crop farmers. We are now developing knowledge-based technologies and management systems that improve input and output productivity in the face of climate change.

New knowledge-based firms, many tied to major seed and equipment firms, provide real-time management recommendations and other services to farmers. These knowledge-based management services frequently guarantee improved profitability or refunded subscription charges. Such information technologies and real-time management services, coupled with tailored seeds from modern plant breeding, monitoring, and variable-rate nutrient and pest control practices tailored to climate and field conditions, are truly the advent of prescription agriculture and may ensure continued yield growth in the face of climate change. The rapid adoption of biotechnology laid the cornerstone for significant yield increases almost two decades ago. In the past decade, modern information and plant breeding systems have helped sustain yields and productivity. Now, the advent of knowledge-based crop management systems further motivates our dynamic forecasts and is likely to bolster yield growth through mid-century. Further reductions in computational, monitoring, and management delivery costs in an era of high land and other prices, is likely to lead to continuing substitution of information and management technologies for more scarce inputs like labor, capital, nutrients, and land. These improved informationbased knowledge systems may also provide improved options for monitoring and managing nutrients, soil loss, pest resistance, and other agricultural externalities.

Acknowledgements We thank participants at the 2014 Berkeley Bioeconomy Conference for helpful comments. This research was sponsored by the U.S. Dept. of Agriculture (USDA) Earth System Modeling program, Award 2013-67003-20642. The views expressed in this paper are those of the authors, and not necessarily those of the U.S. Department of Agriculture or the Economic Research Service. All errors are ours. 


\section{Appendix}

Table 1 Summary statistics, 1960-2011. Baseline specification weather data. Table entries: mean (Std. Dev.)

\begin{tabular}{|c|c|c|c|c|c|c|c|c|}
\hline State & $\begin{array}{l}\text { May } \\
\text { temp. }\end{array}$ & $\begin{array}{l}\text { June } \\
\text { temp. }\end{array}$ & $\begin{array}{l}\text { July } \\
\text { temp. }\end{array}$ & $\begin{array}{l}\text { August } \\
\text { temp. }\end{array}$ & $\begin{array}{l}\text { May } \\
\text { rain }\end{array}$ & \begin{tabular}{|l} 
June \\
rain
\end{tabular} & $\begin{array}{l}\text { July } \\
\text { rain }\end{array}$ & $\begin{array}{l}\text { August } \\
\text { rain }\end{array}$ \\
\hline \multirow[t]{2}{*}{ IA } & 60.1 & 69.5 & 73.7 & 71.2 & 4.3 & 4.8 & 4.3 & 4.1 \\
\hline & (3.2) & (2.1) & (2.3) & (2.5) & (1.5) & (1.9) & (1.8) & (1.9) \\
\hline \multirow[t]{2}{*}{ IL } & 62.4 & 71.7 & 75.3 & 73.3 & 4.4 & 4.2 & 4.0 & 3.6 \\
\hline & (3.4) & (2.0) & (2.1) & $(2.5)$ & (1.7) & (1.5) & $(1.3)$ & (1.3) \\
\hline \multirow[t]{2}{*}{$\mathrm{NE}$} & 58.8 & 68.7 & 74.6 & 72.3 & 3.7 & 3.8 & 3.1 & 2.7 \\
\hline & $(2.8)$ & (2.5) & (2.3) & (2.4) & (1.4) & (1.4) & (1.2) & $(0.94)$ \\
\hline \multirow[t]{2}{*}{ MN } & 54.9 & 64.5 & 69.2 & 66.9 & 3.2 & 4.1 & 3.8 & 3.5 \\
\hline & (3.4) & (2.5) & (2.5) & (2.5) & (1.1) & (1.2) & (1.2) & $(1.0)$ \\
\hline \multirow[t]{2}{*}{ IN } & 61.5 & 70.6 & 74.1 & 72.3 & 4.5 & 4.2 & 4.3 & 3.7 \\
\hline & (3.5) & (2.0) & (2.0) & (2.3) & (1.7) & (1.4) & $(1.5)$ & (1.2) \\
\hline \multirow[t]{2}{*}{ SD } & 56.3 & 66.2 & 72.9 & 70.8 & 3.1 & 3.5 & 2.7 & 2.1 \\
\hline & (2.8) & (2.7) & (2.9) & (2.6) & (1.4) & $(1.2)$ & $(1.1)$ & $(0.71)$ \\
\hline \multirow[t]{2}{*}{ WI } & 55.0 & 64.4 & 69.2 & 67.0 & 3.6 & 4.1 & 3.9 & 4.0 \\
\hline & (3.4) & (2.3) & (2.3) & (2.3) & (1.3) & (1.6) & $(1.3)$ & (1.4) \\
\hline \multirow[t]{2}{*}{$\mathrm{OH}$} & 60.0 & 69.0 & 72.7 & 71.2 & 4.1 & 3.9 & 4.1 & 3.6 \\
\hline & (3.4) & (2.0) & (1.9) & $(2.2)$ & (1.6) & (1.4) & $(1.2)$ & (1.2) \\
\hline \multirow[t]{2}{*}{$\mathrm{KS}$} & 63.7 & 73.4 & 79.0 & 77.0 & 4.0 & 4.2 & 3.5 & 3.2 \\
\hline & (2.8) & (2.4) & (2.4) & (2.6) & (1.5) & (1.3) & (1.6) & (1.3) \\
\hline \multirow[t]{2}{*}{ MO } & 64.2 & 72.8 & 77.5 & 75.8 & 4.9 & 4.4 & 4.0 & 3.6 \\
\hline & (3.0) & (2.1) & (2.1) & (2.6) & (1.8) & (1.5) & (1.6) & (1.4) \\
\hline \multirow[t]{2}{*}{ MI } & 54.1 & 63.6 & 68.3 & 66.6 & 3.1 & 3.3 & 3.1 & 3.4 \\
\hline & (3.4) & (2.3) & (2.3) & $(2.2)$ & (1.1) & $(1.0)$ & $(0.77)$ & $(1.0)$ \\
\hline
\end{tabular}

Note Temperatures for May, June, July, and August are in ${ }^{\circ} \mathrm{F}$. Rainfall for May, June, July, and August are in inches. Note that included regressors vary by state, depending on the results of Bayesian HPD-based tests. See text for data sources

Source NOAA U.S. Climate Divisional Database 
Table 2 Summary statistics, 1960-2011. Alternative specification weather data. Table entries: mean (Std. Dev.)

\begin{tabular}{|c|c|c|c|c|c|c|c|c|}
\hline State & $\begin{array}{l}\text { July } \\
\text { DTR }\end{array}$ & $\begin{array}{l}\text { August } \\
\text { DTR }\end{array}$ & July 90 & $\begin{array}{l}\text { August } \\
90\end{array}$ & $\begin{array}{l}\text { May } \\
\text { event }\end{array}$ & $\begin{array}{l}\text { June } \\
\text { event }\end{array}$ & $\begin{array}{l}\text { July } \\
\text { event }\end{array}$ & $\begin{array}{l}\text { August } \\
\text { event }\end{array}$ \\
\hline \multirow[t]{2}{*}{ IA } & 21.8 & 22.1 & 0.10 & 0.04 & 11.9 & 29.3 & 31.7 & 26.0 \\
\hline & (1.9) & (1.8) & $(0.30)$ & $(0.19)$ & (9.9) & $(17.8)$ & (15.8) & $(17.0)$ \\
\hline \multirow[t]{2}{*}{ IL } & 21.6 & 22.1 & 0.17 & 0.12 & 11.9 & 21.2 & 27.7 & 19.3 \\
\hline & (1.6) & (1.5) & $(0.38)$ & $(0.32)$ & (8.3) & $(11.4)$ & $(12.3)$ & $(11.0)$ \\
\hline \multirow[t]{2}{*}{$\mathrm{NE}$} & 26.2 & 26.5 & 0.48 & 0.21 & 8.8 & 19.7 & 18.3 & 15.1 \\
\hline & (2.0) & (1.8) & $(0.50)$ & $(0.41)$ & (6.5) & (13.2) & $(10.5)$ & (9.9) \\
\hline \multirow[t]{2}{*}{$\mathrm{MN}$} & 23.2 & 23.3 & - & - & 3.9 & 13.1 & 17.1 & 13.8 \\
\hline & (2.0) & (1.7) & - & - & (3.4) & $(8.1)$ & (8.4) & (7.3) \\
\hline \multirow[t]{2}{*}{ IN } & 21.8 & 22.1 & 0.10 & 0.04 & 9.5 & 17.7 & 23.3 & 17.2 \\
\hline & (1.9) & (1.8) & $(0.30)$ & $(0.19)$ & (6.5) & $(9.8)$ & (11.8) & (8.6) \\
\hline \multirow[t]{2}{*}{ SD } & 27.2 & 28.1 & 0.37 & 0.23 & 3.4 & 8.6 & 9.1 & 6.7 \\
\hline & $(2.5)$ & $(2.0)$ & $(0.49)$ & $(0.43)$ & (3.9) & (5.4) & (5.2) & (3.7) \\
\hline \multirow[t]{2}{*}{ WI } & 23.0 & 22.5 & - & - & 4.6 & 12.3 & 14.0 & 14.6 \\
\hline & (1.9) & (1.9) & - & - & (4.0) & (8.8) & (6.9) & $(9.5)$ \\
\hline \multirow[t]{2}{*}{$\mathrm{OH}$} & 22.1 & 22.4 & 0.06 & - & 7.3 & 16.4 & 21.9 & 17.1 \\
\hline & (1.7) & (1.6) & $(0.24)$ & - & (4.8) & $(10.8)$ & (11.6) & (9.5) \\
\hline \multirow[t]{2}{*}{ KS } & 25.3 & 25.6 & 0.85 & 0.67 & 17.3 & 28.5 & 23.9 & 20.5 \\
\hline & (2.1) & (2.1) & $(0.36)$ & $(0.47)$ & $(9.2)$ & (12.3) & $(15.2)$ & $(12.0)$ \\
\hline \multirow[t]{2}{*}{$\mathrm{MO}$} & 22.4 & 23.3 & 0.54 & 0.40 & 19.8 & 26.6 & 28.4 & 25.3 \\
\hline & (2.2) & (1.9) & $(0.50)$ & $(0.50)$ & (11.4) & (14.2) & (17.1) & (13.3) \\
\hline \multirow[t]{2}{*}{ MI } & 23.2 & 22.4 & - & - & 2.0 & 5.0 & 7.9 & 7.4 \\
\hline & (1.4) & (1.4) & - & - & (2.3) & (3.5) & (4.2) & (4.7) \\
\hline
\end{tabular}

Note July and August diurnal temperature range (DTR) are in ${ }^{\circ} \mathrm{F}$. Jul90 and Aug90 are dummy variables indicating if the average maximum temperature is at least $90^{\circ} \mathrm{F}$ for July and August, respectively. Rainfall events for May, June, July, and August are counts indicating at least one in/hr. of rainfall. Blank cells denote regressors that have been dropped due to insufficient variability. See text for data sources

Source NOAA GHCN data and NOAA COOP data 
Fig. 1 Yield forecasts for Iowa and Illinois. Baseline specification, $t$-distributed yields.

Source Authors' forecasts

Fig. 2 Yield forecasts for Minnesota and Wisconsin. Baseline specification, $t$-distributed yields. Source Authors' forecasts

Fig. 3 Yield forecasts for Nebraska and Kansas. Baseline specification, $t$-distributed yields. Source Authors' forecasts
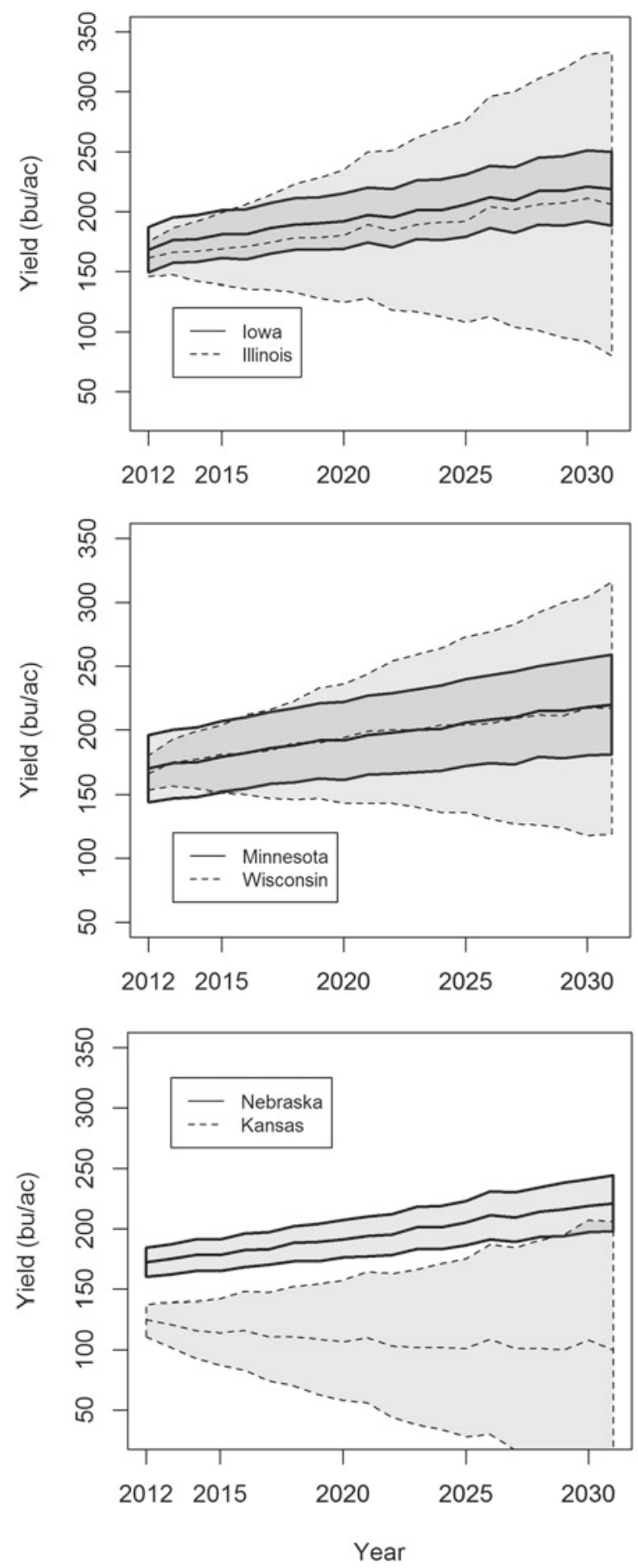
Fig. 4 July rainfall-nitrogen interaction coefficients.

Iowa, baseline specification, beta-distributed yields.

Source Authors' forecasts

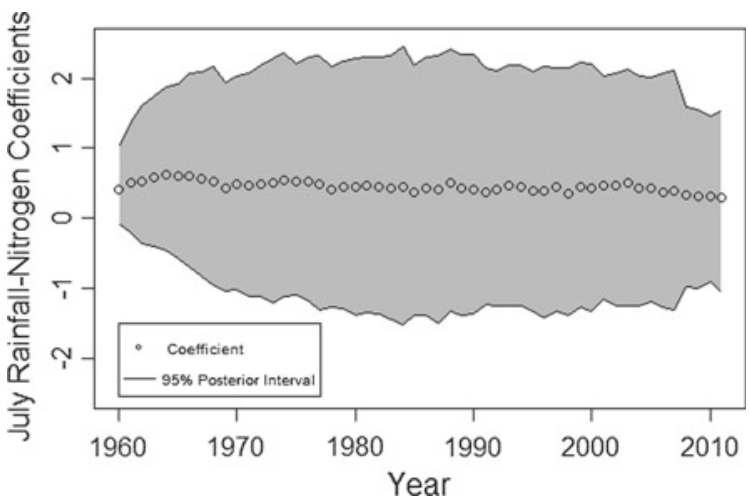

Fig. 5 July event-nitrogen interaction coefficients.

Iowa, alternative specification, beta-distributed yields. Source Authors' forecasts

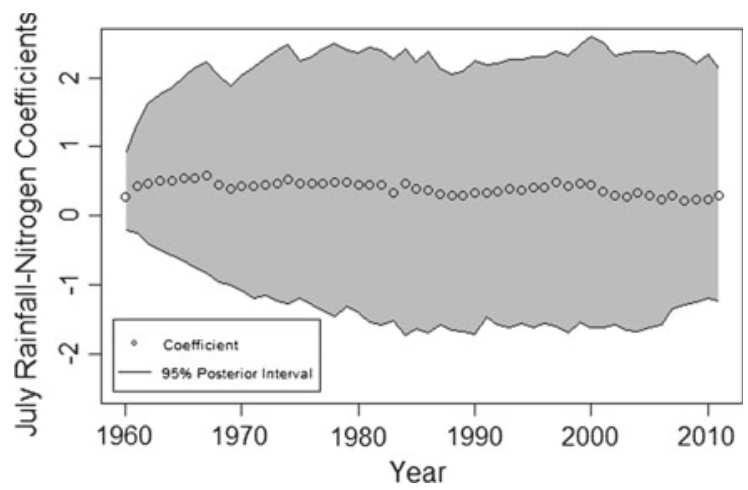


ล

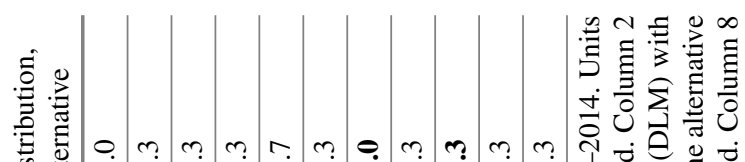

O)

.ే

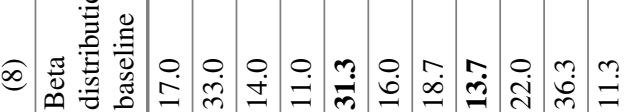

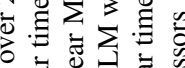

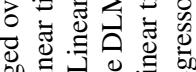

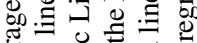

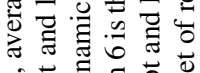

.

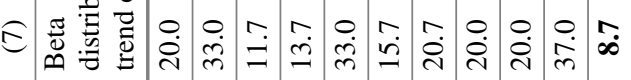

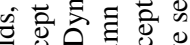

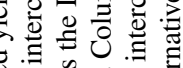

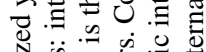

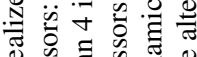

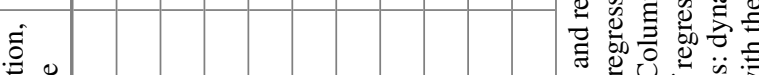

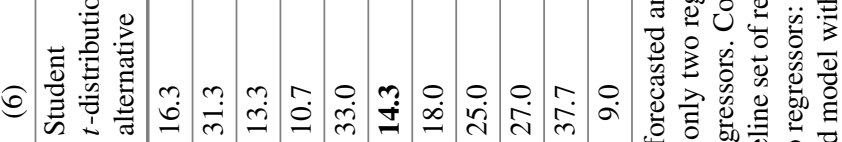

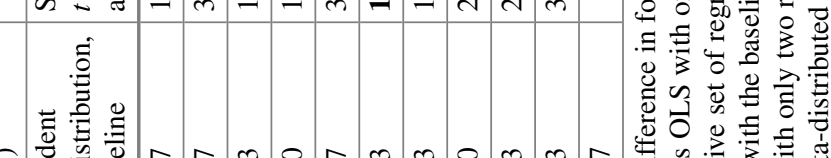

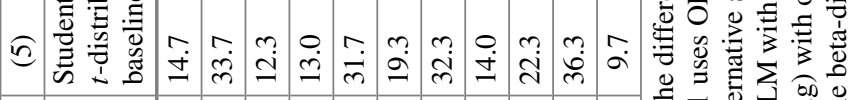
ธิ $\quad$ पुछ

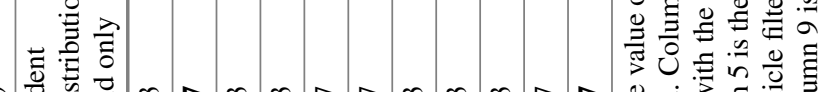

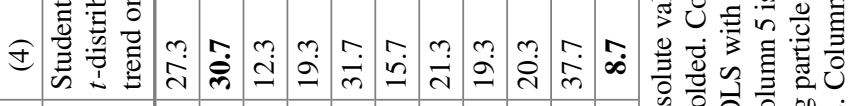

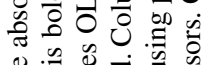

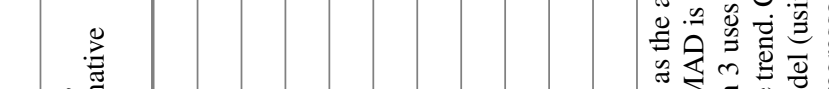

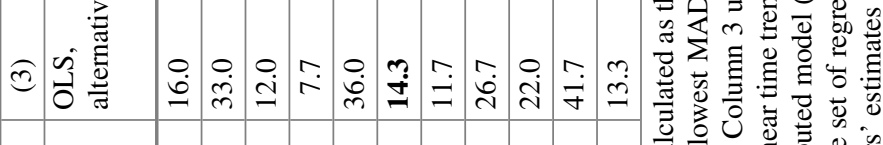

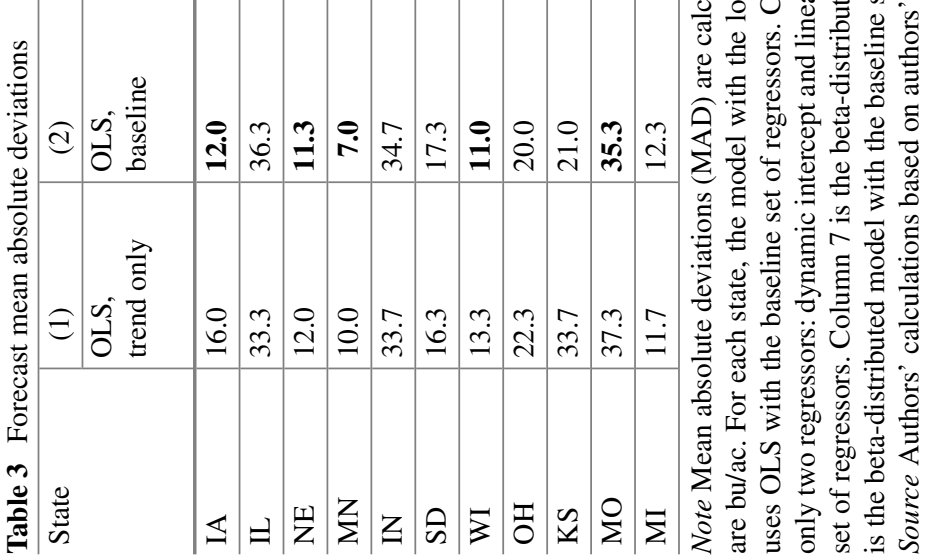




\section{References}

1. Auffhammer, M., Hsiang, S.M., Schlenker, W., Sobel, A.: Using weather data and climate model output in economic analyses of climate change. Rev. Environ. Econ. Policy 7(2), 181198 (2013)

2. Barrows, G., Sexton, S., Zilberman, D.: Agricultural biotechnology: the promise and prospects of genetically modified crops. J. Econ. Perspect. 28(1), 99-120 (2014)

3. Bureau of Reclamation (Reclamation): Downscaled CMIP3 and CMIP5 Climate and Hydrology Projections: Release of Downscaled CMIP5 Climate Projections, Comparison with Preceding Information, and Summary of User Needs. Technical memorandum. U.S. Department of the Interior (2013)

4. Claassen, R., Just, R.E.: Heterogeneity and distributional-form of farm-level yields. Am. J. Agric. Econ. 93(1), 144-160 (2011)

5. Crosbie, T.M., Eathington, S.R., Johnson, Sr. G.R., Edwards, M., Reiter, R., Stark, S., Mohanty, R.G., Oyervides, M., Buehler, R.E., Walker, A.K., Dobert, R., Delannay, X., Pershing, J.C., Hall, M.A., Lamkey, K.R: Chapter 1. Plant breeding: past, present, and future. In: Lamkey, K.R., Lee, M. (eds.) Plant Breeding: The Arnel R. Hallauer International Symposium. pp. 3-50, Blackwell Publishing (2006)

6. da Silva, C., Migon, H.S., Correia, L.: Dynamic Bayesian beta models. Comput. Stat. Data Anal. 55(6), 2074-2089 (2011)

7. Day, R.H.: Probability distributions of field crop yields. J. Farm Econ. 47(3), 713-741 (1965)

8. de Gorter, H., Just, D.R.: The social costs and benefits of biofuels: the intersection of environmental, energy and agricultural policy. Appl. Econ. Perspect. Policy 32(1), 4-32 (2010)

9. Durbin, J., Koopman, S.J.: Time Series Analysis by State Space Methods. Oxford University Press, Oxford (2012)

10. Environmental Protection Agency (EPA): Climate Change Indicators in the United States: Heavy Precipitation. http://www.epa.gov/climatechange/science/indicators/weather-climate/ heavy-precip.html (2013)

11. Fernandez-Cornejo, J., Caswell M.: The first decade of genetically engineered Crops in the United States. Economic Information Bulletin No. 11. United States Department of Agriculture, Economic Research Service (2006)

12. Fernandez-Cornejo, J., Wechsler S.: Bt corn adoption by U.S. farmers increases yields and profits. Amber Waves. United States Department of Agriculture, Economic Research Service (2013)

13. Fernandez-Cornejo, J., Nehring, R., Osteen, C., Wechsler, S., Martin, A., Vialou, A.: Pesticide use in U.S. agriculture: 21 selected crops, 1960-2008. Economic Information Bulletin No. 124. United States Department of Agriculture, Economic Research Service (2014)

14. Fernandez-Cornejo, J., Wechsler, S., Livingston, M.: Adoption of genetically engineered crops by U.S. farmers has increased steadily for over 15 years. Amber Waves. United States Department of Agriculture, Economic Research Service (2014)

15. Foltz, J.D., Kim, K., Barham, B.: A dynamic analysis of university agricultural biotechnology patent production. Am. J. Agric. Econ. 85(1), 187-197 (2003)

16. Groisman, P.Y., Knight, R.W., Karl, T.R.: Changes in intense precipitation over the Central United States. J. Hydrometeorol. 13(1), 47-66 (2012)

17. Harri, A., Erdem, C., Coble, K.H., Knight, T.O.: Crop yield distributions: a reconciliation of previous research and statistical tests for normality. Appl. Econ. Perspect. Policy 31(1), 163-182 (2009)

18. Heisey, P.W., Day-Rubinstein K.: Using crop genetic resources to help agriculture adapt to climate change: economics and policy. Economic Information Bulletin No. 139. United States Department of Agriculture, Economic Research Service (2015)

19. Hendricks, N.P., Peterson, J.M.: Fixed effects estimation of the intensive and extensive margins of irrigation water demand. J. Agric. Resour. Econ. 37(1), 1-19 (2012)

20. Hennessy, D.A., Miranowski, J.A., Babcock, B.A.: Genetic information in agricultural productivity and product development. Am. J. Agric. Econ. 86(1), 73-87 (2004) 
21. Hornbeck, R., Keskin, P.: The historically evolving impact of the ogallala aquifer: agricultural adaptation to groundwater and drought. Am. Econ. J. Appl. Econ. 6(1), 190-219 (2014)

22. Huffman, W.E., Shogren, J.F., Rousu, M., Tegene, A.: Consumer willingness to pay for genetically modified food labels in a market with diverse information: evidence from experimental auctions. J. Agric. Resour. Econ. 28(3), 481-502 (2003)

23. Huffman, W.E.: Contributions of public and private R\&D to biotechnology innovation. In: Carter, C.A., Moschini, G., Sheldon, I. (eds.) Genetically Modified Food and Global Welfare. Frontiers of Economics and Globalization, Vol. 10, pp. 115-147. Emerald Group Publishing Limited (2011)

24. Liu, J., West, M.: Combined parameter and state estimation in simulation-based filtering. In: Doucet, A., de Freitas, N., Gordon, N. (eds.) Sequential Monte Carlo Methods in Practice, pp. 197-224. Springer, Secaucus, NJ (2011)

25. Lobell, D.B., Hammer, G.L., McLean, G., Messina, C., Roberts, M.J., Schlenker, W.: The critical role of extreme heat for maize production in the United States. Nat. Clim. Chang. 3, 497-501 (2013)

26. Lopes, H.F., Tsay, R.S.: Particle filters and Bayesian inference in financial econometrics. J. Forecast. 30(1), 168-209 (2011)

27. Marshall, E., Aillery, M., Malcolm, S., Williams, R.: Climate change, water scarcity, and adaptation in the U.S. Fieldcrop Sector. Economic Research Report 201. United States Department of Agriculture, Economic Research Service (2015)

28. McFadden, J.R., Huffman, W.E.: Consumer valuation of information about food safety achieved using biotechnology: evidence from new potato products. Food Policy 69, 82-96 (2017)

29. McFadden, J.R., Miranowski, J.A.: Climate change and U.S. corn yields: a dynamic Bayesian approach. In: Working paper. Department of Economics, Iowa State University (2014)

30. McFadden, J.R., Miranowski, J.A.: Climate change, technology, and U.S. corn yields. In: Working paper. Department of Economics, Iowa State University U.S. (2015)

31. McFadden, J.R., Miranowski, J.A.: Climate change impacts on the intensive and extensive margins of U.S. agricultural land. In: Working paper. Department of Economics, Iowa State University (2014)

32. McFadden, J.R., Miranowski, J.A.: Climate change: challenge and opportunity to maintain sustainable productivity growth and environment in a corn-soybean bioeconomy. AgBioForum 19(2), 92-111 (2016)

33. McFadden, J.R.., Huffman, W.E.: Consumer demand for low-acrylamide-forming potato products: evidence from lab auctions. Am. J. Potato Res. (2017, forthcoming)

34. Migon, H.S., Gamerman, D., Lopes, H.F., Ferreira, M.A.: Chapter 19: dynamic models. In: Dey, D.K., Rao, C. (eds.) Bayesian Thinking: Modeling and Computation. Handbook of Statistics, Vol. 25, pp. 553-588. Elsevier, Amsterdam (2005)

35. Miranowski, J., Rosburg, A., Aukayanagul, J.: U.S. maize yield growth implications for ethanol and greenhouse gas emissions. AgBioForum 14(3), 120-132 (2011)

36. Miranowski, J.A.: Technology forcing and associated costs and benefits of cellulosic ethanol. Choices 29(1), 1-6 (2014)

37. National Agricultural Statistics Service (NASS): Quick Stats 2.0. http://www.quickstats.nass. usda.gov (2014)

38. National Oceanic and Atmospheric Administration (NOAA): Thunderstorms, Tornadoes, Lightning: Nature's Most Violent Storms. https://www.weather.gov/media/bis/TStorms_Tor_ Lightning.pdf (2014)

39. Ortiz-Bobea, A., Just, R.E.: Modeling the structure of adaptation in climate change impact assessment. Am. J. Agric. Econ 95(2), 244-251 (2013)

40. Pierce, D.W., Barnett, T.P., Santer, B.D., Gleckler, P.J.: Selecting global climate models for regional climate change studies. Proc. Nat. Acad. Sci. 106(21), 8441-8446 (2009)

41. Pole, A., West, M., Harrison, J.: Applied Bayesian Forecasting and Time Series Analysis. Chapman \& Hall, New York (1994)

42. Roberts, M.J., Schlenker, W., Eyer, J.: Agronomic weather measures in econometric models of crop yield with implications for climate change. Am. J. Agric. Econ. 95(2), 236-243 (2013) 
43. Romero-Lankao, P., Smith, J.B., Davidson, D.J., Diffenbaugh, N.S., Kinney, P.L., Kirshen, P., Kovacs, P., Villers Ruiz L.: North America. In: Barros, V.R., Field, C.B., Dokken, D.J., Mastrandrea, M.D., Mach, K.J., Bilir, T.E., Chatterjee, M., Ebi, K.L., Estrada, Y.O., Genova, R.C., Girma, B., Kissel, E.S., Levy, A.N., MacCracken, S., Mastrandrea, P.R., White, L.L. (eds.) Climate Change 2014: Impacts, Adaptation, and Vulnerability. Part B: Regional Aspects. Contribution of Working Group II to the Fifth Assessment Report of the Intergovernmental Panel on Climate Change, pp. 1439-1498. Cambridge University Press, Cambridge, United Kingdom and New York, NY, USA (2014)

44. Rosburg, A., McFadden, J., Miranowski, J.: Managing feedstock supply risk for the development of a U.S. stover biofuel industry. BioEnergy Res. (2017, forthcoming)

45. Schimmelpfennig, D., Lewandrowski, J., Reilly, J., Tsigas, M., Parry, I.: Agricultural adaptation to climate sustainability: issues of long run sustainability. Agricultural Economic Report No. 740. United States Department of Agriculture, Economic Research Service (1996)

46. Schlenker, W., Roberts, M.J.: Nonlinear temperature effects indicate severe damages to U.S. crop yields under climate change. Proc. Nat. Acad. Sci. 106(37), 15594-15598 (2009)

47. Shi, G.: Bundling and licensing of genes in agricultural biotechnology. Am. J. Agric. Econ. 91(1), 264-274 (2009)

48. Shi, G., Chavas, J., Stiegert, K.: An analysis of the pricing of traits in the U.S. corn seed market. Am. J. Agric. Econ. 92(5), 1324-1338 (2010)

49. Smith, S., Cooper, M., Gogerty, J., Löffler, C., Borcherding, D., Wright K.: Chapter 6. Maize. In: Smith, S., Diers, B., Specht, J., Carver, B. (eds.) Yield Gains in Major U.S. Field Crops. pp. 125-171, American Society of Agronomy (2014)

50. United States Department of Agriculture (USDA). U.S. Department of Agriculture Climate Change Adaptation Plan. Government report (2014)

51. West, M., Harrison, J.: Bayesian Forecasting and Dynamic Models. Springer, Secaucus (1997)

52. Xu, Z., Hennessy, D.A., Sardana, K., Moschini, G.: The realized yield effect of genetically engineered crops: U.S. maize and soybean. Crop. Sci. 53(3), 735-745 (2013)

53. Zilberman, D., Liu, X., Roland-Holst, D., Sunding, D.: The economics of climate change in agriculture. Mitig. Adapt. Strateg. Glob. Chang. 9(4), 365-382 (2004)

54. Zilberman, D., Zhao, J., Heiman, A.: Adoption versus adaptation, with emphasis on climate change. Annu. Rev. Resour. Econ. 4, 27-53 (2012) 